\title{
The use of Activity Theory as an analytical tool for the music learning processes.
}

\section{Victoria Kinsella and Martin Fautley}

In this chapter, we propose that an activity theory system (Engeström, 1999), which enables the simultaneous analysis of learning processes alongside the social, historical and cultural structures that shape activity, is suitable for educational research exploring music learning and development across the lifespan.

\section{Introduction.}

Research concerning music development would benefit from an analytical tool that takes into consideration the interconnected elements of culture, environmental structure, and relationship to formations of mind and action. The range of diverse musical learning processes and behaviors present in the classroom and their development involves a range of interconnected interactions. The classroom is a multifaceted environment, where individual identities, dispositions, social and historical perspectives and pedagogical processes exist. Because of these complexities, the researcher must select a methodology that accounts for individual realities but also attributes collective understanding. This methodology must also consider how musical learning takes place, and its relationship to wider socio-cultural elements that shape development. Within this chapter we propose that Activity Theory (AT) (Engeström et al., 1999) is an analytical methodology that provides a lens through which to explore these interactions, and one which also takes into account aspects of cognition.

To frame this, we draw on a case study from a research project exploring composing within the key stage three secondary classroom (11-14). It draws on results from a nationwide study in England, in which professional contemporary composers were employed to work in schools alongside teachers to develop composing pedagogy. This chapter will explore formative assessment strategies adopted by composers and teachers when teaching composing in generalist music classes in England. In this paper, Activity Theory (Engeström et al., 1999) is used to deconstruct the composing process, and focus particularly on the ways in which formative assessment, also known as assessment for learning (AfL), is used to take learning forwards.

\section{Music Education in England.}

In music education there are a complex multiplicity of modalities in both music conceptualization and activity. In a number of jurisdictions, the interrelated aspects of listening, performing and composing are considered as central elements to learning, whereas others are focused more directly onto performing. The considerations in this chapter are rooted in the English system where the research informing this chapter is located, therefore discussions are concerned with what might be termed generalist music education. 
In England there is a National Curriculum which places listening, performing and composing as its central tenets. The statutory program of study which governs this is the English National Curriculum (NC), which is set out in a curriculum document (QCA 2007). The contents of the NC can sometimes be perceived as being eclectic to outside views. Of the three NC elements, composing is often considered the least accessible for teachers (Berkley, 2001). The NC lays out what should have been learned, rather than how it should have been taught. This has the result that in many schools modular schemes of work are produced, which aim to explore a breath of historical and cultural genres, record knowledge transfer, develop a cross fertilization of creative strategies between topics, and collect evidence of musical progress. In particular, collating evidence of thinking in composing is considered a challenge (Fautley, 2010).

The place and purpose of composing as a part of the school curriculum activity has received increasing attention in academic research. Pamela Burnard has researched a variety of approaches to, and outcomes from, the composing process (Burnard, 2000), including how learners make meaning from composing and improvising, and the cognitive and practical mechanisms in place whilst undertaking it (Burnard, 2002; Burnard \& Younker, 2002; 2004). In the context of the English NC, composing often takes place as a collaborative process, and this has formed the locus of investigation for a number of studies (Fautley, 2004; 2005). Social interaction plays a large part in group composing, and this has also been investigated (Miell \& MacDonald, 2000; MacDonald et al., 2002; Major, 2007; 2008), whilst Lewis (2012) has discussed identity issues of teachers and composing. Internationally, the work of Maud Hickey (Hickey, 2001; 2003; 2012) is well known in this area.

This chapter reports on one aspect of the results from a nationwide study in England, Listen, Imagine, Compose (soundandmusic.org), which aimed to address a number of these issues. Exploring and reflecting on the composing process alongside critiquing and investigating new approaches was one of the core aims of the project.

The research aimed to:

- Research and evaluate new approaches to teaching and learning composing in a creative way that address current challenges in state schools;

- Analyze, interrogate and provide answers and insights to the key issues that surround the teaching of creative composing and experimental music;

- Develop models of effective practice that are of national significance to increase the flexibility and relevance of learning for young people aged $11-16$ in music.

Research endeavoring to deconstruct the composing process has been underway for a while, (inter alia (Burnard, 2006; Fautley, 2005; Fautley, 2010), and this paper builds on these. In order to do this, Activity Theory (AT) (Engeström et al., 1999) is employed. There have already been some studies 
using AT (Burnard \& Younker, 2008; Welch, 2007, 2011), and these are a highly useful informant to this chapter.

\section{Activity theory.}

Investigation into individual learning which is mediated by cultural artifacts and membership of a group within a wider community, began with the work of Vygotsky (1978). Vygotsky established a triangular model of action, which explored the relation between human behavior and mediation. This model explored the process through which human behavior is mediated by artifacts that prompt action (Bakhurst 2009:199). Within the classroom, these artifacts include physical tools, such as a musical instrument, or mental aspects, such as language via questioning or discussion. These artifacts form a stimulus between the individual and an outcome. The concept of internalization is central to Vygotsky's model, whereby an individual intervenes and interacts with the artifact, enabling change within the culture (Burnard, 2007). Vygotsky's model of action is represented diagrammatically in a triangle format, as shown in figure one. In this figure, the subject is the individual, who interacts with the mediating artifact, enabling her/him to arrive at the object, which is the outcome of learning. The artifact is the central component that becomes the stimulus affecting practice.

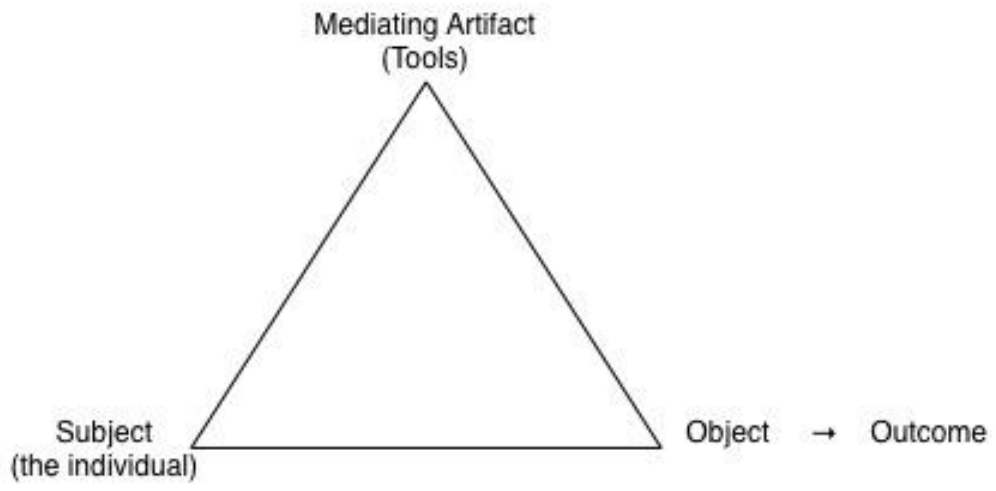

Figure One: Vygotsky's model of mediated action (1978).

Leont'ev (1978) recognized constraints in Vygotsky's concept of action and the singular focus on individual action, not grounded in an understanding of the social structures which impact on the activity. The Leonti'evian perspective therefore attributes a collective motivation to transform an object into a desired outcome (Blin and Munro 2008). This gives direction to action, which is carried out by the subjects and focused towards a goal. However, although the motive is a collective aim, the goal is an individual pursuit. This acknowledges both a collective viewpoint, but also posits the social formation of knowledge as a key component to discovery.

Engeström (1999) also sees the study of artifacts as an important aspect to human functioning. However, according to Engeström (1999), the Vygotskian (1978) and Leont'evian (1978) perspectives do not attribute socially distributed, as well as the importance of artifact-mediated or cultural aspects of human action. Engeström therefore looked at the process of activity further, 
and developed an activity system that allowed both individual learning processes and social interaction to be viewed simultaneously (Figure Two).

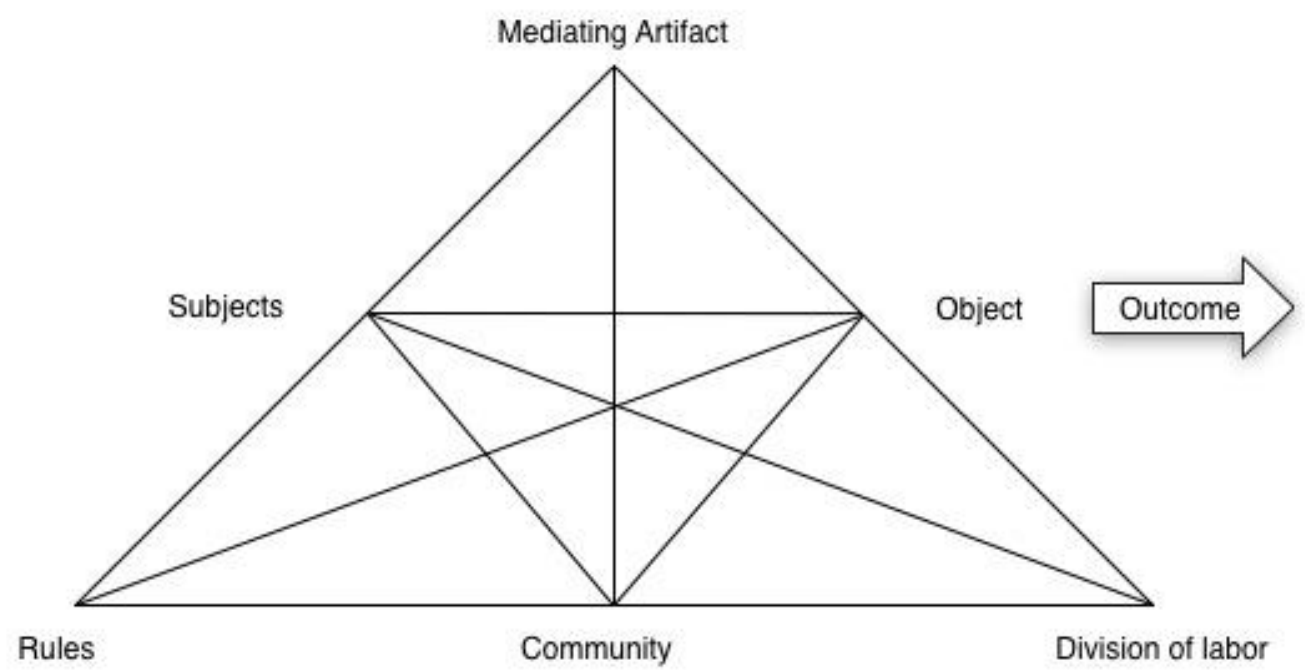

Figure Two: Engeström's structure of human activity system (1999).

Engeström's model of activity adds an additional layer to the Vygotskian model of action, placing the activity within a social context. In the upper part of the figure, Engeström presents a Vygotskian conception, that the 'object' of an action by (or on) a 'subject' is culturally 'mediated' by some form of 'artifact'. This model is extended in the lower part of the figure to encompass both individual and group actions in a collective, interactive activity system in which 'rules', a sense of 'community' and 'division of labor' are evidenced. By identifying the socio-cultural components of an activity, interrelationships between the individual and the community are evidenced. Moreover, by expanding the model to include, the rules, community and division of labor, an activity can be better analyzed.

Through exploring each of the constituents of the AT system, analysis of how activity is taking place can be viewed in conjunction with individual cognition, socio-cultural and historical structures alongside positing music as cultural practice. According to Engeström, this provides an ideal framework through which a holistic view of learning is possible and a multi-faceted viewpoint of the educational environment.

\section{Breaking down the socio-cultural environment.}

In order to highlight the potential impact of activity theory as an analysis tool for use in educational contexts across the lifespan, we shall break down the socio-cultural constituents of the AT system to highlight their significance in the construction of knowledge.

Engeström (2001:7) recognized that participants in an activity system bring with them their own diverse histories and therefore the activity system will be 
multi-layered. For any investigation into music development and pedagogy, it is necessary to consider educational histories that educators and learners come with into the classroom. Identity is pedagogized within educational practices and discourses. These norms create the viability of the subject and their ontology. Central to this identity construction, is the acknowledgment of the cultural-historical character of subjectivity. Subjects constantly renegotiate their partiality in light of experiences. Being aware of the factors that impact subjectivity assists the illumination of the culture of the classroom. Therefore, activity systems take shape and are transformed over time, suggesting a concept of 'historicity' (ibid).

Furthermore, deciphering the macro and micro characteristics that govern the classroom is an important proponent for a rounded perspective. In the AT system, the socio-cultural aspect of activity is conceptualized through associations between rules, division of labor and community. Educational environments operate under specific rules, which shape activity. Rules are not merely teacher directed but externally determined. These discourses can dominate practice and shape how activities are planned. Alongside this, exchange within the activity system itself plays a crucial role in the development of a successful activity. Notions of power lean heavily on pedagogical activities. How divisions of labor are constructed has an impact on the development of the community. Both the rules and division of labor bring into focus the character of the relationships, which affects the sociocultural environment.

Engeström et al (1999) also believed that the object of activity shapes and determines the action. Within the classroom the object refers to the products and outcomes of learning. The construction of an object includes formation of a subject, community, and cultural-historical elements surrounding the classroom. As Engeström et al (1999:107) observed:

"[objects] are constructed with the help and under the influence of historically accumulated collective experience, fixated and embodied in mediating artifacts."

As the object plays a critical role in defining activity, research within the classroom should entail a deep understanding of its purpose and how it is mediated by and through artifacts. Through explorations of their purpose and effectiveness, pedagogical mechanisms can be refined.

By looking at each component of the activity system, examination, reflection, and questioning can occur. Through these explorations practice and relations are open to transformation. These are the product of the 'aggravation' (Engeström 1999), such as when individuals question and deviate from established norms. Through these aggravations an alternative collective viewpoint can be envisioned and practice changed. Engeström's activity theory system provides a way of understanding teaching and learning practices. Through analysis, contradictions within social systems are highlighted. These contradictions present challenges, but offer possibilities for change, which may lead to new rules, division of labor and community. 
Although focusing on one case study, the activity theory model described in this chapter can be adapted to encode other educational situations to reveal development and pedagogy. For the purposes of the analysis in this chapter, Engeström's AT system has been modified to show pedagogical and developmental processes involved in the composing activity.

\section{Using Activity theory to reveal formative assessment approaches in the music classroom: Case study.}

This case study is located in a comprehensive school in the England, where a teacher and class of pupils were engaged in the teaching and learning of music for examination purposes at 14+ years of age. They were participating in a multi-session project during the course of a single school term which involved placing an established composer, and a professional performer (in this case an alto sax player) in the classroom with the teacher and pupils, to work together on developing composing.

The activity theory model has been adapted in figure three to illustrate the components and development of composing within this research. By investigating the labeled constituents of the activity system it became possible to analyze the types of AfL statements made by teachers and composers. It gave the researchers an insight into what was taking place, and how the comments were used. Interestingly, the activity system highlighted significant differences in pedagogical approaches taken by teachers and composers.

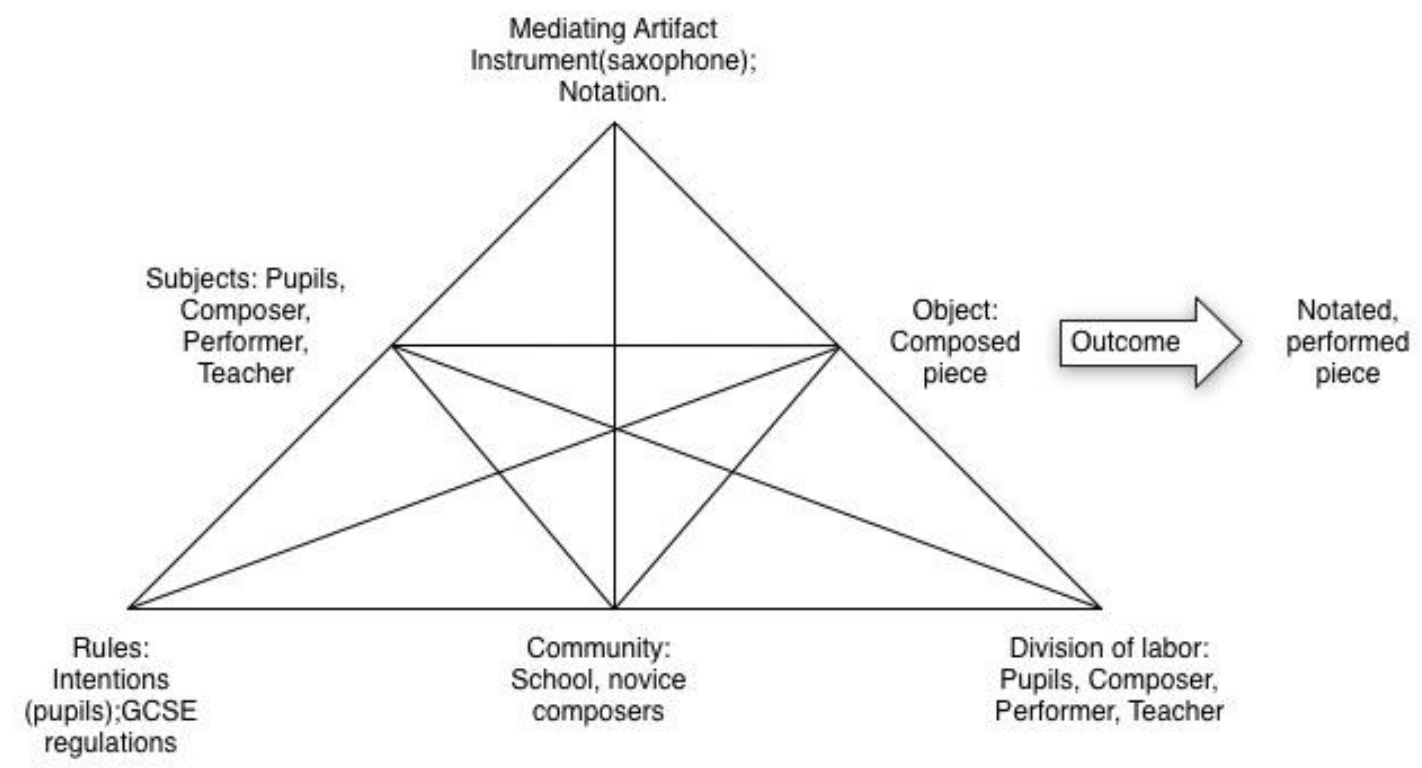

Figure Three: Activity theory revealing formative assessment approaches within the music classroom.

In figure 3, the upper portion of the triangle represents relationships between subjects, people involved in the teaching and learning of composing; mediating artifacts, in this case the pupils were composing for a professional saxophone player, so these are the instrument and the music composed for it; 
and the object, the composed piece of music which emerged from the process. In the lower portion, the community node involves that of peerlearning, alongside other formal and informal support strategies put into place. The division of labor section investigates ways in which the pupils undertake both learning and doing aspects of composing, whilst the teachers and composers are involved in pedagogy. Interestingly the division of labor between teachers and composer overlaps here, and some uniquely definable characteristics in the way in which they develop learning through formative assessment is revealed. This is further explored in the rules section of the AT triangle. Here it was found that the classroom teachers were highly focused on issues concerned with task completion. As this research was conducted in the classroom, there were clear concerns for the teachers about the match with examination syllabi and specifications, curriculum, and assessment. In contrast the AfL comments made by composers were much more likely to be located towards the object node, and would typically focus on quality of task completion.

As there was both a teacher and composer present, the division of labor was shared. This meant that the composer dealt with the compositional process, and the teacher was concerned with matters appertaining to bringing the composition to completion. How this manifested via questioning differed greatly between the teacher and composer.

\section{Discussion}

Throughout the research activity, the role of questioning emerged as a key AfL strategy for the development of composing. We know that questioning is a key feature of classroom practice, but in many cases we also know that questioning can merely elicit factual information (Black et al., 2003). In order to develop higher order thinking, questioning needs to be extended towards understanding and the construction of knowledge. This requires a move away from lower level 'remembering' type questions, towards ones which engage pupils with higher order thinking skills. Through the activity system, and specifically looking at the rules and object to outcomes nodes, we were able to investigate the different ways in which teachers and composers interacted with pupils via questioning. It was observed that composers frequently used higher order thinking questions relating to musicality and composing techniques, and their common stems included:

- 'What would happen' (Bloom: Analysis)

- 'What about' (Application)

- 'I wondered if' (Synthesis/Evaluation)

- 'I think you could'(Application/Analysis)

- 'I can't persuade you' (Evaluation)

- 'You could try' (Application)

- 'I think that' (Evaluation)

The role of the composer's questioning of the pupils was therefore not only to explore learner choice but also: 
.... what they did and why they did it, and of how the resultant composition emerges from such procedural choices. (Fautley, 2014 p.201)

By way of contrast, the questioning employed by the teachers concerned itself with task completion; in other words the teachers were wanting to ensure the learners knew such things as how much time they had left, and what they needed to do to complete on time. The teachers themselves noted that the composers spent a lot longer talking with (not to) the pupils about the music they were producing. This was different to the normal interactions in the classroom. One teacher commented that the role of the teacher could often become one of keeping pupils on-task. This alone raises some potential issues for music educators to think about in terms of how they help individual pupils work through classroom creative learning tasks.

When exploring further these difference between types of AfL, and in particular focusing on the rules node of the activity system, it became apparent practice was often dominated by performative discourses and boundaries which limit time given to exploring pupil intentionality. However, through observing and analyzing teaching and learning processes exampled by the composer, the teachers began to reflect on their own practice and critically evaluate it. This lead to the development of joint teacher and composer planning questions such as: 'What do we want the pupils to learn?'; 'What do we want the pupils to do?'; 'What do the pupils need to have learned before they are able to achieve what we want them to do?'.

There is evidence from using activity theory analysis that key changes occurred throughout the system:

1. The activity system was open to expansive transformation. The social, cultural and musical processes within the classroom were being negotiated and changed through reflection. This was particularly evident in the teacher, who challenged their daily practice lead by the rules of the system towards practice shared with the learner and composer.

2. The activity system was multi-voiced. This lead to a collaborative revision of practice, where teacher and composer reflected both in and on practice.

3. Understanding teacher historicity was important for criticality. Teacher practice was embedded. In order to revision these historical practices teachers needed to observe new practices and critically evaluate the rules node of the activity system, which dominated practice. By exploring rules of the system in relation to outcomes of learning, the teacher refocused the outcome towards musical process and development.

The role of activity theory as a methodology to understand music development across the lifespan.

In this case study AT provided a rich methodological tool for analyzing pedagogy. It provided a means through which not only could interactions be 
investigated but the culture of the classroom was also open to analytic scrutiny. This facilitated a critique of formative assessment processes and questioned the rules, roles and expectations that shaped these discourses. This analysis revealed not only how people think and act but the cultural conditions which gave rise to these discourses.

Activity theory can be used to understand the complex interactions present within an educational environment. The different components of the activity system provides a useful framework to illustrate how pedagogy is developed and its impact on practice. The analytical framework addresses collective, collaborative and individual development which enables teachers, learners, and researchers to reflect in an on action (Shulman 1986).

The process of examining and reflecting can help to depict contradictions. These contradictions are characteristics that disrupt teaching and learning within the classroom. Contradictions are present in every activity system and help to indicate emergent opportunity for development in practice. Engeström et al (1999:67) explored the realm of existing and future contradictions stating:

The zone of proximal development may be depicted as [an] ... area between actions embedded in the current activity with its historical roots and contradictions, the foreseeable activity in which the contradictions are expansively resolved, and the foreseeable activity in which the contradictions have led to contraction and destruction of opportunities.

According to Engeström et al (Engeström, 1999) contradictions are historically accumulating. Experience formulates pedagogy, and practice is defined by these previous learning experiences. Contradictions can therefore become embedded and if not reflected upon can become rooted in practice. Within the example case study the multi-layered analysis, generated deep reflection on the relationships and the top-down, bottom-up perspectives, which impinged a composing pedagogy. Contradictions posed included accountability rules, divisions of labor and opposed views of the outcomes of learning. Through reflexive investigations of formative assessment processes, the teacher revealed cultural and historical factors that framed their pedagogy causing contradictions.

It is important for these contradictions to be questioned, challenged, and reflected upon in order to transform activity. The term 'aggravation' is utilized by Engeström (2001:136-7) as a notion of probing existing norms and conditions. He states:

As the contradictions of an activity system are aggravated, some individual participants begin to question and deviate from its established norms. In some cases, this escalates into collaborative envisioning and a deliberate collective change effort. An expansive transformation is accomplished when the object and motive of the activity are reconceptualized to embrace a radically wider horizon of possibilities than the previous mode of activity. 
In order to critique practice the contradictions presented through the activity system need to be challenged. These contradictions can be internal, directly impacting teaching and learning within the classroom or external, factors driven by socio-cultural elements of teaching and learning, such as policy. Challenging these contractions involves deviating from historical and established norms.

\section{Conclusion.}

So what is the role of activity theory across the lifespan? Activity theory helps to generate rich data on interactions and make visible the contradictions present. Moreover, these contradictions can then be analyzed in relation to the object of activity, learning. This analysis is a primary means through which a transformation in practice can occur, where the participants can learn to overcome the contradictions within the system (Avis 2009).

In educational settings meaning is created both individually and collectively, but is also affected by structural contexts within the institution. An important feature of activity theory is its suitability for examining and analyzing individual and collective pedagogic practices. By looking at each node of the activity system separately we can examine, reflect and question approaches to teaching and learning. In the case study, AT enabled deeper understandings of formative assessment strategies employed by teachers and composers in the classroom. It also points ways of developing practice. It outlined ways in which composing pedagogy could be taken forward, and ways in which researchers can use AT to access otherwise closed-off areas of classroom activities and interactions to reveal underlying classroom ontologies. Activity theory deconstructed the composing process for pedagogic purposes, and broke down teaching and learning into observable components. Pedagogy and pedagogic content knowledge (Shulman, 1986) does not develop easily, however, by using an activity theory system as an analytical tool, teachers, composers and researchers were able to observe, label, and discuss practice leading to change.

The AT methodological framework is not fixed to certain activities but open for use across contexts. Not only is it open for the analysis of activities but can be adjusted to explore educational problems, relationships, cognition and cultural resources that influence changes. Its strength is its adaptiveness to varying educational contexts and stages of learning.

\section{Endnote}

The authors would like to acknowledge the support of the Esmée Fairbairn foundation for funding the research on which this chapter is based, and the organizations Sound and Music, and the Birmingham Contemporary Music Group for providing the frameworks and people to operationalize this program of activity and research.

\section{References.}

Avis, J. (2009) Transformation or Transformism: Engeström's Version of 
Activity Theory? Educational Review, 61(2), pp. 151-165.

Bakhurst, D. (2009) Reflections on activity theory. Educational Review, 61(2), pp. 197-210.

Berkley, R. (2001) Why is teaching composing so challenging? A survey of classroom observation and teachers' opinions. British Journal of Music Education, 18, 2, 119-38.

Black, P., Harrison, C., Lee, C., Marshall, B. \& Wiliam, D. (2003) Assessment for Learning: Putting it into practice, Maidenhead, Open University Press.

Blin, F. \& Munro, M. (2008) Why hasn't technology disrupted academics' teaching practices? Understanding resistance to change through the lens of activity theory. Computers \& Education, 50(2), pp. 475-490.

Bloom, B. S. (1956) Taxonomy of Educational Objectives, Handbook I: The Cognitive Domain. , New York, David McKay Co Inc.

Burnard, P. (2000) How children ascribe meaning to improvisation and composition. Music Education Research, 2, 1, 7-23.

Burnard, P. (2002) Investigating children's meaning-making and the emergence of musical interaction in group improvisation. British Journal of Music Education, 19, 2, 157-72.

Burnard, P. (2006) Telling half the story: making explicit the significance of methods and methodologies in creative education. Music Education Research, 8(2), 143-152.

Burnard, P. (2007) 'Reframing creativity and technology: promoting pedagogic change in music education '. Vol. 1, Journal of Music, Technology and Education., Intellect Ltd

Burnard, P. \& Younker, B. A. (2002) Mapping Pathways: fostering creativity in composition. Music Education Research, 4, 2, 245-61.

Burnard, P. \& Younker, B. (2004) Problem-Solving and Creativity: Insights from Students' Individual Composing Pathways. International Journal of Music Education.

Burnard, P. \& Younker, B.A. (2008) Investigating children's musical interactions within the activities systems of group composing and arranging: an application of Engeström's Activity Theory. International Journal of Educational Research, 47(1), p. 60-74.

Engeström, Y. (1999) 'Activity theory and individual and social transformations.'. In Y. Engeström, R. Miettinen \& (Eds.), R.-L. P. (Eds), Perspectives on activity theory, pp. 19-38. Cambridge, Cambridge University Press.

Engeström, Y., Miettenen, R. \& Punamaki, R. L. (Eds) (1999) Perspectives on Activity Theory, Cambridge, Cambridge University Press.

Engeström, Y. (2001) Expansive Learning at Work: toward an activity theoretical reconceptualization. Journal of Education and Work, 14 (1), pp. 133-156.

Fautley, M. (2004) Teacher intervention strategies in the composing processes of lower secondary school students. International Journal of Music Education, 22, 3, 201-18.

Fautley, M. (2005) A new model of the group composing process of lower secondary school students. Music Education Research, 7, 1, 39 - 57.

Fautley, M. (2010) Assessment in Music Education, Oxford: Oxford University Press. 
Fautley, M. (2014) 'Assessment of composing in higher music education: purposes and practices'. In Burnard, P. (Ed), Developing Creativities in Higher Music Education: International perspectives and practices, pp. 199-210 London, Routledge.

Hickey, M. (2001) 'More or less creative? A comparison of the composing processes and products of "highly creative" and "less creative" children composers'. 2nd International research in Music Education conference, Exeter, UK.

Hickey, M. (2003) 'Creative Thinking in the Context of Music Education'. In Hickey, M. (Ed), Why and how to teach music composition: A new horizon for music education, pp. 31-54. Reston, Virginia, MENC.

Hickey, M. (2012) Music Outside the Lines: Ideas for Composing in K-12 Music Classrooms, Oxford University Press.

Leont'ev, A. N. (1978) Activity, consciousness and personality. Englewood Cliffs, NJ: Prentice Hall.

Lewis, R. (2012) Composing the curriculum: Teacher identity. British Journal of Music Education, 29, 02, 153-61.

MacDonald, R., Miell, D. \& Mitchell, L. (2002) An investigation of children's musical collaborations: the effect of friendship and age. Psychology of Music, 30, 2, 148.

Major, A. (2007) Talking about composing in secondary school music lessons. British Journal of Music Education, 24, 2, 165-78.

Major, A. (2008) Appraising composing in secondary-school music lessons. Music Education Research, 10, 2, 307-19.

Miell, D. \& MacDonald, R. (2000) Children's Creative Collaborations: The Importance of Friendship when Working Together on a Musical Composition. Social Development, 9, 3, 348-69.

Qualifications and Curriculum Authority (QCA) (2007) The National Curriculum: Statutory requirements for key stage 3 and 4. London: QCA.

Shulman, L. S. (1986) Paradigms and Research Programs in the Study of Teaching: A Contemporary Perspective. In Wittrock, M. C. (Ed) Handbook of Research on Teaching (3rd Ed), pp.3-36 New York: Macmillan.

Soundandmusic.org (2014) Listen, Imagine, Compose Website URL http://www.soundandmusic.org/projects/listen-imagine-compose Accessed December 2014

Vygotsky, L. (1978) Mind in Society, Cambridge, Massachusetts, Harvard University Press.

Welch, G. (2007) Addressing the multifaceted nature of music education: An activity theory research perspective. Research Studies in Music Education, 28, 1, 23.

Welch, G. (2011) 'Culture and gender in a cathedral music context: An activity theory exploration'. In Barrett, M. (Ed), A Cultural Psychology of Music Education, pp. 225-58. Oxford, Oxford University Press. 